УДК 37

УДК $10.21661 / \mathrm{r}-552847$

\title{
Сафина Г.Г.
}

\section{ПЕДАГОГИЧЕСКИЙ ПОТЕНЦИАЛ МАГИСТРАТУРЫ В РАЗВИТИИ ИССЛЕДОВАТЕЛЬСКОЙ КОМПЕТЕНЦИИ СТУДЕНТОВ ВУЗА}

Аннотация: магистратура создает потенциальные возможности для решения проблемы обеспечения условий для саморазвития исследовательской компетенции студентов вуза. Магистратура содействует стимулированию научной и научно-методической деятельности студенческой молодежи; индивидуализачии магистерских программ на базе бакалаврской подготовки.

Ключевые слова: студент, исследовательская деятельность, магистратура, педагогический потенциил, магистр.

Safina G.G.

\section{PEDAGOGIC POTENTIAL OF MASTER'S PROGRAMME IN THE DEVELOPMENT OF RESEARCH COMPETENCE OF TERTIARY STUDENTS}

Abstract: master's programme creates potential for solutions to issues of laying the groundwork for self-development of research competence of tertiary students. Master's programme contributes to stimulation of research and scientific-methodological activities of students as well as individualization of Master's programmes on the basis of baccalaureate.

Keywords: student, research activity, Master's programme, pedagogic potential, Master.

В настоящее время в сфере высшего профессионально-педагогического образования России на повестке дня стоит вопрос о необходимости создания всех условий для саморазвития исследовательской компетенции студентов вуза. Эта необходимость обусловлена общественной потребностью в инициативных и самостоятельных субъектах, отвечающих за собственное благополучие и 
благополучие своей страны; потребностью в специалистах новой формации, способных решать задачи, связанные с образованием подрастающего поколения; потребностью в профессионалах, готовых к постоянной самореализации в избранной сфере деятельности; потребностью в модернизации педагогической науки в направлении обогащения научных знаний о личностном и профессиональном саморазвитии молодых людей. Данная проблема может успешно решаться на уровне магистратуры, направленной на подготовку выпускников вуза, мотивированных к овладению новыми специальностями. Магистратура создает потенциальные возможности для решения проблемы обеспечения условий для саморазвития исследовательской компетенции студентов вуза. Магистратура содействует стимулированию научной и научно-методической деятельности студенческой молодежи; индивидуализации магистерских программ на базе бакалаврской подготовки; привлечению магистрантов к участию во многих видах научных исследований и выполнению различных российских и международных грантов; обеспечению условий для адаптации магистрантов уже в процессе обучения к будущей профессиональной деятельности и т. д. По мнению В.С. Сенашенко, практика магистратуры нацелена на подготовку специалиста высокой квалификации, способного осуществлять современные исследовательские подходы при организации своей профессиональной деятельности [4]. Как уже было отмечено выше, целью системы магистратуры в вузе является подготовка кадров для профессиональной школы. Эта система ориентирована на научно-исследовательскую деятельность студентов, что, по мнению исследователя. Г.А. Бордовского, считается наилучшим вариантом для подготовки магистров образования, имеющих четкое понимание всей сложности формирования себя как специалиста в избранной профессии [1]. При этом, важно понимать, что магистратура - это не просто второй уровень высшего образования, это еще и прекрасная возможность повышения свой квалификации по уже полученной профессии.

Система магистратуры сфокусирована на создании специальных условий для обучающихся, направленных на организацию их научной деятельности. При этом, вузы уделяют большое внимание развитию и личностных компетенций 
студентов, увязанных с формированием у них коммуникационных навыков работы в научной среде, навыков написания научных статей и умения грамотной их презентации и т. д. Все это направлено на то, чтобы выпускники магистратуры не только стали профессионалами в своей узкой области, но и были подготовлены к работе в постоянно меняющихся социально-экономических условиях. Отсюда, учеба магистрантов дает им хороший старт научной карьеры, предоставляет возможности приобретения опыта общения с компетентными специалистами и т. д.

Следует отметить, что уже сами магистерские образовательные программы предусматривают как освоение теории, так и практическую подготовку магистрантов к продуманной и четко организованной научно-исследовательской деятельности, которую курируют, как правило, преподаватели высшей квалификации (доктора наук). Они помогают магистрантам выбрать направление своего научного исследования, по окончанию работы, над которой далее и защищается магистерская диссертация. В ходе обучения магистранты приобретают также и педагогические компетенции, что дает им право (в отличие от бакалавров) преподавать в вузе. Процесс обучения в вузе предполагает, что магистранты обязательно должны заниматься научно-исследовательской деятельностью, в которую вовлечены профессорско-преподавательский состав вуза и сами магистранты. При этом, магистранты получают определенный навык в организации своей научно-исследовательской работы, что отражается в определении ими объекта и предмета исследования, задач исследования, построения гипотезы и т. д. Более того, исследовательскую деятельность магистрантов можно назвать определенным способом самовыражения, что дает им возможность проявлять свои лучшие качества с точки зрения интеллектуального потенциала. Пройдя этап самоопределения в процессе изучения учебных дисциплин, магистрант затем погружается в область своей научной работы. В ходе обучения в магистратуре магистрант выполняет контрольные работы, пишет реферат, курсовую работу, выступает на семинарах, коллоквиумах и студенческих научных конференциях. По одной из рекомендуемых тем, и исходя из личного желания, магистрант набирает 
фактологический материал по своей теме, подвергает его анализу и далее уже пишет собственно свою научную работу. Таким образом, исследовательская деятельность магистрантов представляет собой некий синтез учебной исследовательской работы и внеучебной научно-исследовательской деятельности.

С учетом перехода российского образования на государственные стандарты третьего поколения вопрос о формировании исследовательской компетенции стал одним из значимых задач, поскольку она рассматривается сегодня не просто в виде узкоспециального качества (например, для определенной группы профессионалов), но и как важнейшая характеристика индивида, который является представителем той или иной профессиональной сферы. Отсюда, как считает исследователь П.В. Середенко, в сфере образования необходимо ввести положение о включении методов исследовательского обучения в образовательную практику, результатом чего должно стать качественное развитие исследовательских способностей у студентов [5]. На этой основе при подготовке студенческой молодежи к исследовательской деятельности разрабатываются соответствующие образовательные технологии [3]. Практически это осуществляется таким образом, что в самом процесс обучения в магистратуре удельный вес времени отводится самостоятельной работе. В этой связи, педагогический потенциал системы магистратуры заключается в следующем: а) магистрантов готовят к овладению методологией научного познания на фундаментальном уровне; б) профильная подготовка магистрантов осуществляется в профессионально близкой им области исследований; в) процесс обучения в магистратуре теснейшим образом связан с исследовательской практикой магистрантов; г) на каждой стадии обучения в магистратуре организуются тренинги по формированию исследовательской компетенции; д) активно используется система мониторинга исследовательской работы магистрантов. При этом, в системе магистратуры у магистрантов культивируется установка на развитии у них убежденности в необходимости данной работы; на важность достижения высокого уровня теоретических знаний и формирования у себя исследовательской компетенции. На этой основе формулируются и определенные требования к уровню подготовки магистра, в перечень 
которых обычно входят способность молодого человека работать в сфере фундаментальных наук; его готовность к осуществлению научно-исследовательской деятельности на основе самообразования и саморазвития и т. д. В результате учебы в магистратуре будущий магистр должен демонстрировать знания для реализации идей в исследовательской деятельности; использовать практические знания, необходимые в данной области для последующего развития новых идей; демонстрировать аналитические умения для формирования взаимосвязи между различными объектами своего исследования; демонстрировать способность к пониманию нестандартных контекстов изучаемой многофакторной проблемы; демонстрировать умения интегрировать знания из междисциплинарных областей с целью поиска решения в условиях ограниченности информации; демонстрировать автономию в выборе научного направления, а отсюда, понимание изучаемого процесса и т. д. Как итог, у магистранта, по мнению А.А. Вербицкого, формируется способность к моделированию своей будущей профессиональной деятельности, обеспечивая, тем самым, для себя условия перехода учебной деятельности в профессиональную плоскость [2]. А это значит, что магистрант на основе сформированной исследовательской компетенции приобретает также и сопутствующие ей другие компетенции: системные компетенциии (способность учиться и саморазвиваться; умение работать в автономном режиме; способность к анализу и синтезу; способность порождать новые идеи; умение акцентировать актуальные вопросы по обсуждаемой теме; умение вести научную дискуссию; способность к ясному и логичному изложению содержимого представляемого доклада; умение структурировать содержание научной статьи в формате реферата; наличие исследовательских навыков; способность и готовность к применению знаний на практике; способность адаптироваться к новой возникшей ситуации; стремление к достижению качества своих научных исследований; стремление к успеху в предпринимаемом научном поиске и т. д.); $u н$ струментальные компетенции (способность к организации и планированию своей научной деятельности; умение работать с научной литературой; навыки работы с цифровой техникой; овладение новыми компьютерными программами; 
навыки управления информацией (ее нахождение и анализ); умение организовывать письменную коммуникацию на родном языке; знание второго языка; способность к принятию решений в нестандартных ситуациях; готовность к тщательной подготовке по основам профильных знаний и т. д.); межличностные компетенциии (умение и готовность работать в единой команде; - умение работать в междисциплинарной команде; способность общаться со специалистами из других областей; способность к самокритическому анализу своей деятельности; способность к рациональному распоряжению своим временем в не ущерб общим целям; умение убеждать единомышленников, а также соглашаться с их доводами в пользу принятия общего мнения; демонстрация упорства как стремления к достижению намеченной цели; способность к инициативе и готовность к принятию на себя новых обязательств, связанных с решением возникшей научной проблемы; способность к выражению позитивных чувств и отношений; демонстрация к стрессоустойчивости при решении трудных задач; постоянная ориентация на возможные изменения в характере работы и т. д.).

В этой связи, как считает исследователь Е.А. Слепенкова [6], в системе магистратуры можно выделить следующие компоненты его педагогического потенциала: обучающий компонент (способствует выполнению научного исследования и овладению необходимыми для этого методологическими знаниями и умениями, как-то: знаниями о современной проблематике в области данной конкретной научной проблемы; умением составлять творческий план исследовательской задачи, структурировать содержательную ее часть с поэтапными результатами; умением анализировать полученные данные и корректировать выводы; умением владеть современными технологиями сбора информации; навыками обработки и интерпретации полученных экспериментальных; умением составлять индивидуальную программу, направленную на выполнение конкретного задания в соответствии с темой магистерской диссертации и т. д.); личностно-развивающий компонент (способствует формированию познавательных интересов; развитию рефлексивных способностей и логического мышления; развитию умения обозначать актуальность проблемы в намеченном виде 
деятельности; повышению уровня соответствия общественным требованиям своего научного исследования; целенаправленному формированию значимых ценностных ориентаций; повышению интереса к межкультурной коммуникации и т. д.); социиально-компетентностный компонент (способствует умению выявлять данные, необходимые для решения поставленной исследовательской задачи; способствует умению использовать новые способы и средства в поисковой деятельности; способствует умению реализовывать методологические требования и нормативы при написании научной работы; способствует умению разрабатывать программу исследовательской деятельности и обеспечивать ее поэтапную реализацию; способствует умению выбирать необходимую информацию для выстраивания концепции своей деятельности; способствует умению представлять результаты проведенного исследования в виде отчета с грамотным изложением доклада; способствует умению самостоятельно осваивать инновационные методы исследования; способствует повышению интеллектуального и культурного уровня с целью выстраивания траектории будущего профессионального развития; способствует умению обогащать себя новыми знаниями по актуальному направлению своего исследования с целью преодоления методологических противоречий и т. д.); стимулирующуий компонент (способствует удовлетворению запросам и потребностям магистрантов; дает возможность выстраиванию новых способов самостоятельной работы; учитывает склонности конкретного магистранта; ориентирует на потенциальные возможности магистранта; дает возможность самовыражению и самоактуализации в данном виде деятельности; обеспечивает условия для преодоления таких трудностей, как владение письменной речью и четкого изложения своих теоретических и эмпирических результатов исследования; способствует достижению синтеза общей методологии, методологии гуманитарного исследования и собственно проблем научно-исследовательской работы; стимулирует магистрантов к достижению соответствующего уровня получаемого образования; способствует социальной защите магистранта и его адаптации к новым условиям конкурентной среды; стимулирует культивирование у магистрантов установку на обладание знаниями 
для осуществления общественно-полезной деятельности в рамках существующих социальных условий и т. д.).

Таким образом, обучение студента в магистратуре представляет собой существенный ресурс для расширения его профессиональных возможностей в рамках приобщения к науке, а главное - на основе своего научного исследования возможности испытать свой образовательный потенциал на практике в качестве молодого специалиста системы образования.

\section{Сиисок литературы}

1. Бордовский Г.А. Возможности многоуровневой системы подготовки педагогических кадров в решении перспективных задач модернизации отечественного образования / Г.А. Бордовский // Информационный бюллетень. - 2005. №1(28). - C. 6-10.

2. Вербицкий А.А. Новая образовательная парадигма и контекстное обучение / А.А. Вербицкий. - М., 1999. - 75 с.

3. Поддъяков А.К. Исследовательское поведение. Стратегии познания, помощь, противодействие, конфликт / А.К. Поддъяков. - М.: Эребус, 2000. - 200 с.

4. Сенашенко В.С. Магистратура: второе рождение / В.С. Сенашенко // Высшее образование в России. 1993. №3. С. 92-99

5. Середенко П.В. Развитие исследовательских умений и навыков у будущих педагогов / П.В. Середенко // Среднее профессиональное образование. №1. - 2008. - C.62-64

6. Слепенкова Е.А. Педагогическая научно-исследовательская деятельность в профессиональной подготовке учителя отечественной школы в ХХ веке: что изменилось за 100 лет? / Е.А. Слепенкова // Вопросы образования. - №1. 2007. - C.94-108

\section{References}

1. Bordovskii, G. A. (2005). Vozmozhnosti mnogourovnevoi sistemy podgotovki pedagogicheskikh kadrov $\mathrm{v}$ reshenii perspektivnykh zadach modernizatsii otechestvennogo obrazovaniia. Informatsionnyi biulleten', 1(28), 6-10. 
2. Verbitskii, A. A. (1999). Novaia obrazovatel'naia paradigma i kontekstnoe obuchenie., 75. M.

3. Poddiakov, A. K. (2000). Issledovatel'skoe povedenie. Strategii poznaniia, pomoshch', protivodeistvie, konflikt., 200. M.: Erebus.

4. Senashenko, V. S. Magistratura: vtoroe rozhdenie. Vysshee obrazovanie v Rossii. 1993. 3. S. 92-99.

5. Seredenko, P. V. (2008). Razvitie issledovatel'skikh umenii i navykov u budushchikh pedagogov. Srednee professional'noe obrazovanie, 1, 62.

6. Slepenkova, E. A. (2007). Pedagogicheskaia nauchno-issledovatel'skaia deiatel'nost' v professional'noi podgotovke uchitelia otechestvennoi shkoly v XX veke: chto izmenilos' za 100 let?. Voprosy obrazovaniia, 1, 94.

Сафина Гузель Габдельнуровна - аспирант, Институт психологии и образования ФГАОУ ВО «Казанский (Приволжский) федеральный университет», Казань, Россия.

Safina Guzel Gabdelnurovna - postgraduate student, Kazan (Volga region) Federal University, Kazan, Russia. 